\title{
Design of Intelligent Logistics System Based on JIT Material Distribution Plan
}

\author{
Yunrui Wang, Zhengli Wu, Xuwen Zhao \\ School of Mechanical Engineering, Xi'an University of Science and Technology, Xi'an, Shanxi \\ Province, China
}

\begin{abstract}
With increasingly high demands of personalized requirements and delivery time of customers, material distribution must be on time with guaranteeing the flexibility. This became one of the most critical technologies for companies to achieve the intelligent logistics. Aiming at the issues which is large batch size and serious accumulation in the material distribution of a specific enterprise, PCBA board was chosen as the research object in this study. Through analyzing the process of material distribution, the economic distribution batch model and the distribution kanban model were set up. Besides, the ANDON system has been designed and a just-in-time distribution system for materials was eventually constructed. This system greatly reduces material distribution personals and time, which saves distribution expenditures and combines this system with the currently used MES system by the company to achieve the cooperative control of plan and materials, thus providing guarantee for intelligent logistics system. At present, this system has been used in enterprises, making good advancement.
\end{abstract}

Keywords: Intelligent logistics; JIT material distribution; economic distribution batch; distribution Kanban; ANDON system.

\section{Introduction}

Intelligent manufacturing is not only a breakthrough for China's industrial transformation, but also a new engine for reshaping the competitive advantage of the manufacturing industry. It is premeditated by the general public in theory and practice to represent the future direction of manufacturing[1]. In the research of intelligent manufacturing, intelligent logistics is one of the things that need to be focused. With the change of industrial model, customers' requirements for product personality and response cycle are getting higher and higher, which requires a highly flexible automation of the material distribution model, which can respond quickly to orders[2].Therefore, when researching intelligent logistics, it is necessary to realize the problem of the JIT material distribution is delivered in the necessary amount at the necessary time, and that problem must be solved[3].

There have been extensive researches on material distribution at home and abroad. The theoretical production instruction watch-board and the picking kanban is proposed in the thesis of Material Distribution on the General Assembly Line of Mixed-Flow Cars under JIT Production Mode[4]. In the thesis of Research on Material Distribution Optimization of Y Company's Production Line[5], small batch and multiple frequency distribution of materials is realized, but there is no systematic design for the distribution kanban.Therefore, this article takes a company that produces products related to LED as the research object, combining the characteristics of intelligent logistics, using the concept of lean thinking and the common methods of industrial engineering [6] to construct a material distribution system. In order to achieve the JIT material distribution and reduce distribution costs.

\section{The Present Situation of Material Distribution in Factory}

\subsection{Status of Material Distribution in the Factory}

The receiving card is the main product of the company and the demand is large. It consists of PCBA board, label, packaging material and other materials. Because of the size and lightness of the label, companies are now using multiple methods for one-time delivery. PCBA board and packaging materials are loaded in a large volume and these two kinds of logistics distribution are based on the consumption situation of the site. The material keeper carries out large-scale but low-frequency 
distribution according to experience, which makes the number of wire edge materials extremely uneven, sometimes causing excessive accumulation and occupying channels, and sometimes there will be shortage of materials, which brings great trouble to the production organization. Therefore, the material PCBA board is selected as the research object, and the punctual design of material distribution is carried out.

\subsection{Material Distribution Status}

The measurement unit of the PCBA board is pcs, and loaded in a cardboard box or an electrostatic box. The loading capacity is $60 \mathrm{pcs} /$ carton, and daily planned output is $24000 \mathrm{pcs}$. The current working time of this enterprise is 8 hours per day. Manual forklift delivery is adopted, and the batch is 21 boxes. As shown by the arrow in Fig.1, the delivery route is first delivered from the warehouse to the unpacking area, then the unpacked PCBA board is sent to the line edge temporary storage area of the three production lines line1, line 2 and line 3 . The total distance is $88.3 \mathrm{~m}$ through field measuring.PCBA board is delivered from the warehouse to the line temporary storage area, and its material distribution process is shown in Fig.2. The name and time of the picking, unpacking and feeding operations are shown in Tab.1. The total time of picking is $454 \mathrm{~s}$ (7.6min); the total unpacking process is $1436 \mathrm{~s}(23.9 \mathrm{~min})$; the total feeding time is $247.6 \mathrm{~s}(4.1 \mathrm{~min})$; the total material delivery time is $2137.6 \mathrm{~s}(35.6 \mathrm{~min})$, and the bottleneck process takes the longest time among the unpacking process.

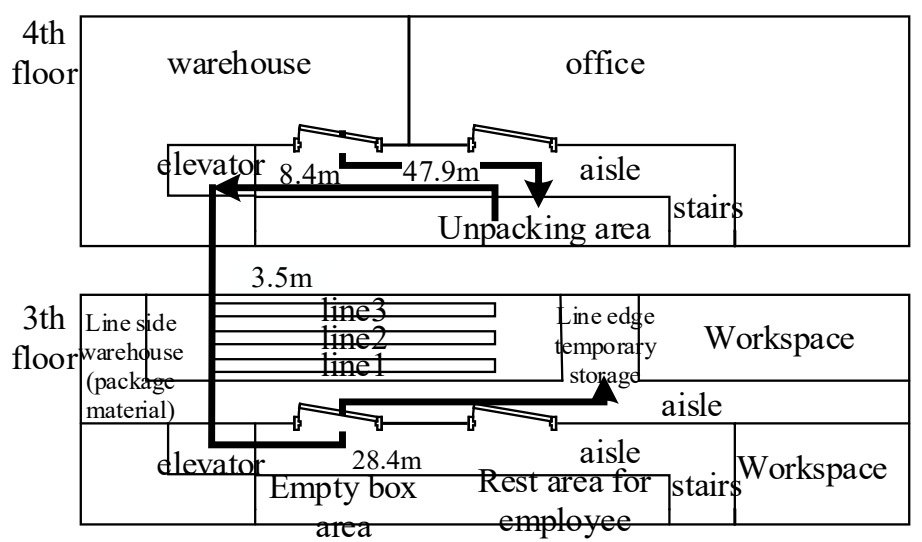

Fig.1 Delivery Route

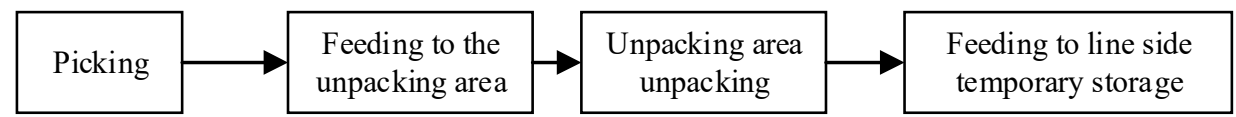

Fig.2 Material Distribution Process

\section{JIT Material Distribution Plan Design}

\subsection{Improvement of Bottleneck Process}

According to the analysis of the production status of the enterprise, combining with the communication with the supplier, a new plan is proposed for the unpacking process. The supplier is allowed to use the electrostatic box inside the factory to put the PCBA board directly into the turnover box electrostatic box. Thus, unpacking process in the factory has been canceled, which is beneficial to improve material distribution more effective, ESD static protection, reduce the packaging cost of suppliers, and save natural resources and social resources. 
Tab.1 Process Operation Name and time

\begin{tabular}{|c|c|c|}
\hline Process & Job name & $\begin{array}{c}\text { Average } \\
\text { time } \\
\text { (unit: } S \text { ) }\end{array}$ \\
\hline \multirow{4}{*}{$\begin{array}{l}\text { Picking } \\
\text { process }\end{array}$} & $\begin{array}{l}\text { In the fourth-floor warehouse, moving the whole box of PCBA board to the } \\
\text { manual forklift takes total of } 21 \text { boxes are required for one delivery. }\end{array}$ & 147.0 \\
\hline & Move the manual forklift to the fourth-floor unpacking area & 160.0 \\
\hline & Unloading operation & 147.0 \\
\hline & Moving Carton to unpacking station & 168.0 \\
\hline \multirow{3}{*}{$\begin{array}{l}\text { Unpacking } \\
\text { process }\end{array}$} & Unpacking operation & 63.0 \\
\hline & Unpacking inspection Checking appearance & 1037.0 \\
\hline & $\begin{array}{c}\text { Unpacking the materials that have been placed in the electrostatic box and } \\
\text { moving them to the manual forklift }\end{array}$ & 168.0 \\
\hline \multirow{3}{*}{$\begin{array}{l}\text { Feeding } \\
\text { process }\end{array}$} & Move the manual forklift to the fourth-floor elevator & 28.0 \\
\hline & $\begin{array}{l}\text { Moving from the fourth floor elevator to any of the three production-line side } \\
\text { which is temporary storage areas on the third floor. }\end{array}$ & 114.6 \\
\hline & Unloading operation & 105.0 \\
\hline
\end{tabular}

\subsection{JIT Material Distribution Plan Design}

To accomplish delivery materials on time, the in-process inventory between the current process is designed, and the distribution kanban is designed to control the time of delivery of materials.

\subsubsection{Determination of Delivery Time}

To achieve the JIT material distribution, the total delivery time should be less than 21 boxes of a production line. Production line consumption time is expressed as follows:

$$
\begin{gathered}
T T=\frac{t * 3600}{Q_{1}}=\frac{8 \times 3600}{24000}=1.2 \mathrm{~s} / \mathrm{pcs} \\
T_{\text {耗 }}=\frac{T T * Q_{2}}{60}=\frac{1.2 \times 21 \times 60}{60}=25.2 \mathrm{~min}
\end{gathered}
$$

In the formula, TT is Demanding beat; $T_{h}$ is the time that the production line consumes 21 boxes; $Q_{2}$ is 21 boxes of material quantity.

The maximum time for a material handler to distribute materials to a production line is calculated as follows:

$$
\begin{aligned}
\text { Maximum delivery time } & =\frac{\text { The production line consumes } 21 \text { boxes of time }}{\text { Number of production lines }} \\
& =\frac{25.2}{3}=8.4
\end{aligned}
$$

Therefore, the maximum delivery time is $8.4 \mathrm{~min}$ to ensure the normal production of the production line. After the unpacking process has been canceled, the picking and feeding procedures are analyzed in accordance with the 5W2H questioning technique and the ECRS principle [7-8]. The picking process has been canceled. One keeper delivers directly the material to the line edge temporary storage area of three production lines line1, line2 and line3.The new distribution route is measured and calculated on-site as shown by the arrow in Fig.3. By the measuring and calculating on site. The total distance is $78.6 \mathrm{~m}$. The production cycle after equalization of the three production lines is 
$2.98 \mathrm{~s} / \mathrm{pcs}$ for line $1,2.54 \mathrm{~s} / \mathrm{pcs}$ for line 2 , and $3.4 \mathrm{~s} / \mathrm{pcs}$ for line 3 .At the same time, the material distribution tool is changed to a turnover frame to cancel the unloading operation and achieve the purpose of meeting the delivery time. The total delivery time after improvement refers to the removal of the static electric box from the fourth-floor warehouse to the manual forklift. The single box handling time is $8 \mathrm{~s}$, then the manual forklift is moved to the temporary storage area of third production line side, which takes 270.2 s. The time to carry the $n$ boxes is $(8 n+270.2) s$.

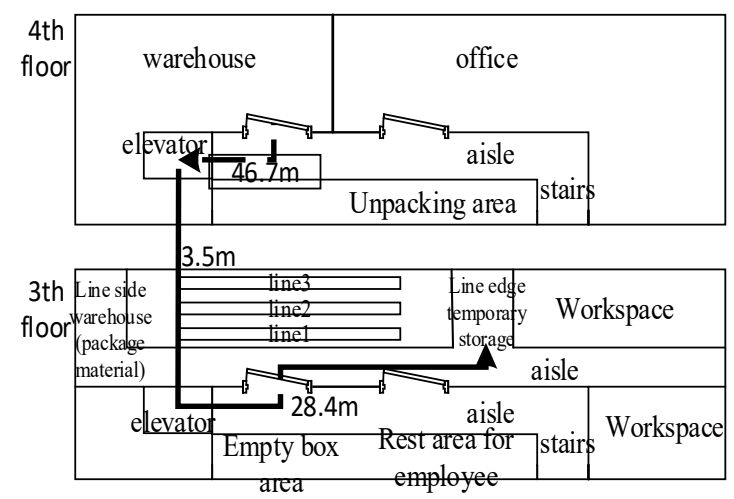

Fig.3 New Delivery Route

\subsubsection{Establishment of Economic Distribution Batch Model}

The PCBA board is distributed using a quantitative ordering model [9]. Daily total cost calculation formula is expressed as follows:

Daily total cost of distribution $=$ daily distribution cost + daily storage cost

$$
T C=\frac{D}{Q} C_{t}+\frac{Q}{2} C_{i}
$$

Derivation to get the economic distribution batch formula is expressed as follows:

$$
E O Q=\sqrt{2 D C_{i} / C_{t}}=\sqrt{2 \times 400 \times 0.88 / 5}=12
$$

In the formula, TC is the total cost ; $\mathrm{D}$ is the daily demand; $\mathrm{C}_{\mathrm{t}}$ is the total cost of single material distribution 5 yuan; $\mathrm{C}_{\mathrm{i}}$ is the unit inventory day cost 0.88 yuan/box; $\mathrm{Q}$ is the delivery batch; $E O Q$ is the best economic delivery batch. Among them $\mathrm{D}$ is calculated as follows:

$$
D=\frac{\text { Daily planned output }}{\text { One carton load }}=\frac{24000}{60}=400
$$

\subsubsection{Establishment of the Distribution Kanban Inventory Model}

Three types of distribution sign inventory models are established as shown in Fig. 4. The three stocks are defined as: warning stock, which is the minimum stock, that is, the production line material demand during the interval from the warehouse to the line side temporary storage area. Early warning inventory, which is for the redistribution point inventory, the available inventory minus the difference between the materials required for the production line in the three-production line delivery cycle. The maximum inventory is the material that has been delivered to the line-side temporary storage area and can be directly used for production, that is, the sum of the distribution batch and the remaining inventory on the line side. 


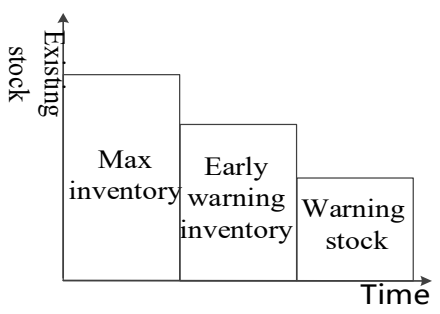

Fig.4 Inventory Mode

Three types of kanban data for three production lines are calculated based on the inventory models. It is known that the production cycle after equalization of three production lines is $2.98 \mathrm{~s} / \mathrm{pcs}$ for line1, $2.54 \mathrm{~s} / \mathrm{pcs}$ for line 2 , and $3.4 \mathrm{~s} / \mathrm{pcs}$ for line 3 . From the time of carrying $\mathrm{n}$ boxes $(8 \mathrm{n}+270.2) \mathrm{s}$, the time for carrying 12 boxes of materials is calculated to be $6.1 \mathrm{~min}$. The cycle time formula is expressed as:

$$
\begin{aligned}
& \text { period time }=\text { Time to carry } 12 \text { boxes of material } * \text { Number of production lines } \\
& \qquad=6.1 \times 3=18.3
\end{aligned}
$$

The calculating formulas of the three types of stocks are as follows, and results are shown in Tab.2.

$$
\begin{gathered}
\text { Warning stock }=\frac{\text { Time to carry } 12 \text { boxes of material }}{\text { Production beat }} \\
\text { Early warning inventory }=\text { Economic distribution batch }-\frac{\text { period time }}{\text { Production beat }}
\end{gathered}
$$

Maximum inventory $=$ Maximum early warning inventory - Warning stock + EOQ

Tab.2 Distribution Kanban Data

\begin{tabular}{ccccc}
\hline & Production & line1 & line2 & line3 \\
\hline Stock/bo & Maximum inventory & 16 & 13 & 16 \\
& Early warning inventory & 6 & 4 & 6 \\
Warning stock & 2 & 3 & 2 \\
\hline
\end{tabular}

\subsubsection{ANDON System Design}

Based on distribution watch-board, the ANDON system has been introduced to establish the material request using radio transmission technology[10].Yellow and red indicated buttons are installed next to the production line, and line keeper distribute materials according to the delivery watch-board. When the distribution kanban material quantity is at the maximum value of the warning stock, the production line employee must press the red button in the ANDON system to call the material. During the period between the maximum warning stock and the Early warning stock, the production line employees can press the yellow button in the ANDON system at any time in this interval for calling materials. In the warning inventory between the maximum and maximum inventory, production line keeper cannot call. According to the ANDON system, the material delivery personnel will deliver the goods on time according to the economic delivery batch.

\subsection{Improve the Effect}

The design of the JIT material distribution system was applied to the production of enterprises. The delivery time was reduced from $35.6 \mathrm{~min}$ to $6.1 \mathrm{~min}$, and the number of keepers was reduced from 8 to 1 , and the material occupancy area was reduced from $28 \mathrm{~m} 2$ to $2.88 \mathrm{~m} 2$, which can save enterprises 22,000 yuan per month. The executive rate of the plan has been improved by combining this system with the MES system which is in use. 


\section{Conclusion}

The JIT distribution of materials is one of the important technologies for enterprises to realize intelligent logistics. Through the optimization of the material distribution procedures, a JIT material distribution system consisting of economic distribution batch, distribution kanban, and lamp system is constructed. Combining this system with the MES system which is being used can achieve the coordinated control of planning and materials. Through the implementation of the enterprise, it has achieved obvious results. It will be the next step to combine the automated Material conveying apparatus with the distribution system, and design the reasonable distribution route and realize the intelligent logistics.

\section{References}

[1]. Lu Tie, Han Na. Intelligent Manufacturing: Global Trends and China Strategy [J]. People's Forum. Academic Frontiers, 2015, (11): 6-17.

[2]. Fang Dianjun, Li Wei. Construction of Intelligent Logistics System Supporting Intelligent Manufacturing [J]. Logistics Technology and Application,2015, (6):88-92.

[3]. L ü Liyong,Wang Tianmiao,Xiao Xiujian.Study on Pulling Production Method Based on Distribution BOM[J]. Modular Machine Tool \& Automatic Processing Technology, 2002, (11): 29-31.

[4]. Cai Miao.Material Distribution in the Assembly Line of Mixed-flow Cars under JIT Production Mode[J].Manufacturing Automation,2006,(28):233-235.

[5]. Li Chen. Research on Material Distribution Optimization of Y Company Production Line [D]. Beijing Jiaotong University, 2015.

[6]. Mustapha Sali, Evren Sahin.Line feeding optimization for Just in Time assembly lines: An application to the automotive industry[J],International Journal of Production Economics, 2016,(174):54-67.

[7]. Liu Hongwei, Liu Jianglong, Wang Yang. Study on the efficiency improvem-ent method of steel pipe loading and packaging operation[J]. Industrial Engineering and Management, 2015,20 (4):152-155.

[8]. Pornthipa Ongkunaruk, Wimonrat Wongsatit. An ECRS-based line balancing concept: a case study of a frozen chicken producer[J]. Business Process Management Journal. 2014,20(5):678692 .

[9]. Wang Han min, Ge Maogen, Zhang Wei. Study on Material Distribution System of Mechanical Product Assembly Process for MES [J]. Combined Machine Tool \& Automatic Processing Technology,2012, (9):98-102.

[10]. Li Rui,Lei Haihai,Wang Tao.Analysis and Application of Andon System in Field Logistics[J].Industrial Engineering,2009,12(2):119-121. 